\title{
$\mathrm{CPR}^{\mathrm{m}}$ : Adopting An Out-Of-Discipline Innovation
}

Kay E. Strong, (Email: kstrong@bgsu.edu), Bowling Green State University, Firelands

\begin{abstract}
Calibrated Peer Review ${ }^{\mathrm{TM}}$ (CPR) is a web-based instructional tool that encourages "writing gain for students" without adding "grading pain for the instructor!" The use of CPR provides students frequent opportunities to hone both writing as well as peer review skills in a guided environment. And once an assignment is authored, instructors have little to do beside monitor progress and arbitrate possible grading complaints! The four phase process of the Calibrated Peer Review ${ }^{\mathrm{TM}}$ reinforces learning of the content material and provides immediate assessment feedback. Students access the assignment by logging into CPR. Phase one involves the preparation and submission of the student's text response to the writing assignment. During phase two the student evaluates three instructor written calibrations (high quality, mid quality and low quality) of the same assignment using pre-specified rubrics assessing content and style. An unsuccessful outcome prompts a return to the calibrations and a retry. A successful outcome moves the student forward into phase three. The software randomly selects three anonymous peer assignments. Using the same evaluation criteria the student assesses each assignment. At phase four, the student is presented his/her own assignment for self-review. Time limits at each phase insure timely completion of the assignment in full. The CPR tool provides immediate feedback on student performance at each phase. At the conclusion the CPR tool produces a complete set of results corresponding to performance at each phase; a score for the text entry, a score for the three calibrations, a score for the three peer reviews, a self-assessment score and concluding overall score. To bypass problems commonly associated with students reviewing student work, CPR has built in a set of "weighting" factors based on standard deviations which are reflected in the student's own scores. Given its discipline-independent nature, Calibrated Peer Review ${ }^{\mathrm{TM}}$ makes an excellent instructional management tool to encourage students to read for content, master the content, write-to-learn, as well as, critically review writing.
\end{abstract}

Key Words: Technology in the Classroom, Calibrated Peer Review ${ }^{\mathrm{TM}}$, Assessment of Writing

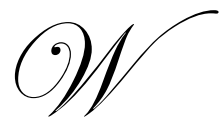

riting in its varied formats, one-minute papers to elaborate research papers, is recognized as a strategy to promote deeper understanding of core theories and arguments specific to a discipline. Writing-across-the-curriculum advocates have long argued that writing is a 'powerful instrument of thought (Palmini 1996, p. 205)' capable of creating learning. Clear writing is a reflection of clear thought (Petr 1998). Cameron (1998) identifies writing as a desirable technique for shifting the in-class learning process from instructor to student-centered. Writing facilitates real world information literacy and development of electronic skills (Wight, 1999). For the non-writing teacher, Elbow (1994) advocates low stakes writing, writing-to-learn. Write-to-learn emphasizes the demonstration of learning, understanding, remembering and figuring out what is not yet known rather than pure writing mechanics. Despite evidence in favor of writing as a valued learning strategy, the prospect of mountains of papers to grade is sufficient to dose the flames of even the most ardent enthusiast.

Enter Calibrated Peer Review ${ }^{\mathrm{TM}}(\mathrm{CPR})^{1}$, a web-based instructional tool that encourages "writing gain for students" without adding "grading pain for the instructor!" The overall goal of $\mathbf{C P R}^{\mathbf{T M}}$ is to produce stronger

${ }^{1} \mathbf{C P R}^{\mathrm{TM}}$ is a trademark of the Regents of The University of California. 
readers and writers. The multi-stage process encourages students to read for content, master the content, write-tolearn, think critically and develop evaluative reviewing skills.

Developed by Dr. Orville Chapman at UCLA in 1995, CPR $^{\text {TM }}$ is a digital writing and peer editing instructional tool with extensive usage in the hard sciences (chemistry, biology, earth science, geology, engineering, physiology, neuroscience and medicine), yet the applicability of $\mathbf{C P R} \mathbf{R}^{\mathbf{T M}}$ transcends both level and discipline. The user-base currently includes over 500 institutional accounts ranging from school to university level, more than 2,500 courses having used CPR with over 70,000 students exposed to the process (6/05). Well-developed CPR $^{\text {TM }}$ assignments according to Carlson and Berry (2003) comprise learning opportunities that accommodate both the higher-order cognitive processes emphasized by Bloom's taxonomy (1956) and the intellectual growth model Perry (1981) outlines. CPR ${ }^{\mathrm{TM}}$ fully meets the Salemi criteria (2002) as an active learning experience by providing students opportunity to practice economics in a controlled environment, to receive feedback from fellow students for mutual gain, to enhance the variety of learning approaches employed, to respond to positive expectations and to gain from diversity of perspectives. Extensive feedback in the iterative $\mathbf{C} \mathbf{P} \mathbf{R}^{\mathbf{T M}}$ process clarifies student thinking and corrects misunderstandings (formative assessment) and the built-in data collection-interpretation tools culminate in the production of evaluation reports on student achievement (summative assessment). Both types of assessment are desirable according to Walstad (2005) for improving instruction and measuring student achievement. Goffe and Sosin (2005) indicate that while computer technology may not be the next leap forward in learning methods, "students are increasingly ready to use it $\ldots$ and expect it to be a part of their college experience." $\mathbf{C P R}{ }^{\mathrm{TM}}$ 's electronic, asynchronous and discipline-independent learning environment affords a perfect opportunity to leap frog current technology practices (electronic communication, web-enhanced assignments and course management) in economics and meet student expectations, while incorporating performance enhancing active learning opportunities.

\section{DOES IT WORK?}

Numerous studies involving $\mathbf{C P R}^{\mathbf{T M}}$ usage in undergraduate Science-Technology-EngineeringMathematics (STEM) education document quantitative learning gains for students. Physiologist Pelaez (2001) conducted a test using the following hypothesis: $\mathbf{C} \mathbf{P R}^{\mathrm{TM}}$ increases achievement on both essay and standard textbook multiple choice assessment. Her conclusion after use of three (3) CPR assignments was that the mean midterm essay scores were significantly better for topics taught using CPR than traditional instruction; mean scores on multiple choice items on the mid-term were significantly better for topics taught using CPR than using traditional instruction and mean total essay exam scores at the end of the semester were significantly better for topics taught using CPR than traditional instruction. Cervato, Rudd and Ridky (2003) performed a similar test with earth science students. Their conclusions are supportive, “...statistical results from this implementation show that students who completed the CPR assignment performed better on exam questions as compared to students who completed a different type of writing assignment." Heise, Palmer-Julson and Su (2002) corroborate that "[w]ith the traditional writing assignments, students' writing skills showed no improvement between the first and second essay, while CPR students demonstrated improvement in technical writing and critical thinking skills between the two [geology] assignments." Russell's findings (2005) across three different universities independently documenting student performance taught using CPR assignments reports a $+10 \%$ gain for students than those taught through traditional lecture and textbook methods alone. Additionally, citing a national study of 10 courses in multiple disciplines, Russell cites that students' ability to review and evaluate content for accuracy, argument and logic improve irrespective of the academic level. Furman and Robinson (2003), however, derive a less stellar conclusion on engineering student achievement: "We saw some indications that CPR improved the students' writing abilities. The average CPR scores improved from $65 \%$ to $77 \%$ from those students who completed all three assignments. However, the scores for their writing itself (as judged by their peers) remained flat. The improvement in overall scores may reflect an increase in mastering the CPR system rather than an improvement in writing skills." On the whole, statistical evidence supports the premise that $\mathbf{C P R}^{\mathbf{T M}}$ increases student course achievement.

\section{HOW TO MAKE IT WORK}

This is my second year using $\mathbf{C P R}^{\mathrm{TM}}$ in Introduction to Economics (ECON 200). A course populated by a mix of thirty-five traditional and non-traditional students cutting across all degree areas from manufacturing and 
business to social work. My course objective is to use the power of economics as a tool of analysis for understanding contemporary social economic issues. Writing has been the fundamental learning strategy employed. Employment of $\mathbf{C P R}^{\mathrm{TM}}$ has greatly facilitated my desire to continue using this learning strategy. Given the ability to adapt personal library assignments, the upfront investment of time and energy per assignment is lessened with each succeeding round of usage. Three $\mathbf{C P R}^{\mathbf{T M}}$ assignments substitute for formal exams over approximately seventy-five percent of the course coverage. Two formal exams are given, one five weeks into the semester and one at the end of the semester, neither are comprehensive.

The $\mathbf{C P R}^{\mathrm{TM}}$ instructional tool requires the instructor to create an assignment then launch it by following succinct activation instructions.

\section{$1^{\text {ST }}$ : CREATING A NEW ASSIGNMENT:}

To create an assignment the instruction may choose to select an assignment from the Server database or author a unique assignment. The majority of 135 edited assignments currently housed in the UCLA Server library are science-based. Fortunately, the "new assignment" authoring tool is a straightforward six-step process. I use a sample assignment authored for my economics course.

\section{Step 1. Provide an Assignment Title: “It Just Isn't So: My Autobiography (4/07)"}

Step 2. Delineate Assignment Goals: A simple copy-paste from a document works well.

\section{Learning Goals:}

The objective of the Introduction to Economics course is to use the power of economics as a tool of analysis for understanding contemporary social economic issues. The analysis is undertaken utilizing fundamental economic concepts with emphasis on alternative economic policies.

In completing this course, students will:

(a) Demonstrate a command of basic characteristics of the American and global economy by using this knowledge to critically evaluate economic outcomes.

(b) Demonstrate a command of basic economic theory by using this theory to make predictions and to analyze alternative economic policy options.

(c) Demonstrate the ability to communicate in both oral and written forms by presenting arguments and evidence clearly and concisely.

(d) Demonstrate the ability to engage in and understand moral reasoning with respect to economic issues by recognizing the implicit value conflicts present in all economic policy debates.

(e) Demonstrate the ability to engage in (creative) problem solving using basic economic theory.

(f) Demonstrate the ability to engage in critical thinking as a part of the analysis of economic problems.

Step 3. Identify any Source Material you wish students to access without leaving CPR.

\section{Source Material:}

This assignment assumes that the student has had prior instruction on Income Distribution and Poverty in the United States.

The textbook, Economics of Social Issues (17th ed.) by Sharp-Register-Grimes, presents this material in Chapter 7. While the textbook is your primary resource, authoritative news articles and other credible web sources may be used to supplement your understanding. 


\section{Source Material Resources:}

Income, Poverty and Health Insurance in the United States - Bureau of Census

URL: http://www.census.gov/hhes/www/income/income04.html

WORKING HARD, FALLING SHORT - The Annie E. Casey Foundation

URL:http://cpr.molsci.ucla.edu/cpr/data/designers/d/d05579/assignments/200015/resources/res003/file/working_hard falling short_new.pdf

Standing Up for Children Now - The Children's Defense Fund

URL:http://cpr.molsci.ucla.edu/cpr/data/designers/d/d05579/assignments/200015/resources/res004/file/Econ200

Chapter 7 Stand_Up_for_Children_Now.pdf

National Center for Children in Poverty - NCCP URL: http://www.nccp.org/pub_swf05.html

HTML - Adding HTML URL: http://www.w3schools.com/html/html_layout.asp

Step 4. Provide Instructions (Student Instructions, Guiding Questions and a Writing Prompt)

\section{Student Instructions:}

This writing assignment substitutes for a formal EXAM.

Before you begin to write, please, study your class notes, re-read the assigned chapter and review the other readings at the course website. You will be looking for answers to the "Guiding Questions."

Follow the links under "Source Material" which contain more information than you may actually need to complete this assignment.

Once you are prepared for the exam, begin the Writing Assignment.

The required length is at least $\mathbf{5 0 0}$ words.

Work off-line (word processing program) so that you can easily SAVE and store your work in-progress. When you are finished, copy and paste the assignment into the CPR TEXT window.

To maintain paragraphs in your assignment, use the HTML tag " $<\mathbf{p}>$ " before each new paragraph.

DON'T forget to "Preview Text" before submitting.

\section{Guiding Questions:}

In preparing your autobiography, your writing assignment must minimally address the issues raised by the following statements:

1. Identify the association between the current distribution of income and poverty in the U.S.

2. Use factual evidence to support your claims about the distribution of income and poverty.

3. Identify real causes of today's poverty and the primary victims in the U.S.

4. Acknowledge the economic consequences of poverty for both victims and society.

5. Assess the Bush Administration's leadership in alleviating poverty in the U.S. 


\section{Text Entry Directions (Writing Prompt):}

As John F Kennedy once said "The great enemy of the truth is very often not the lie -deliberate, contrived, and dishonest- but the myth-persistent, persuasive, and unrealistic. Only when we break through the myths, the myths of poverty, the myths of inequality, the myths of empire, will we reveal the pure and unobstructed truth. And only with this truth revealed will reality, in our eyes, be reality: clear, unhindered, and free." (11 June 1962)

Myths about those who live a life of poverty abound. These myths often serve to justify not acting in their behalf. In 2004 the Bureau of Census reported that 37 million Americans fell into the ranks of the impoverished. The percentage of Americans has increased every year since 2000. You are one of these 37 million Americans. You will use the facts about poverty to narrate your autobiography. In doing so, you will dispel some of the common myths about the impoverished.

Required Text Entry Length: minimum 500 words

A Student View Of The Text Entry Phase.

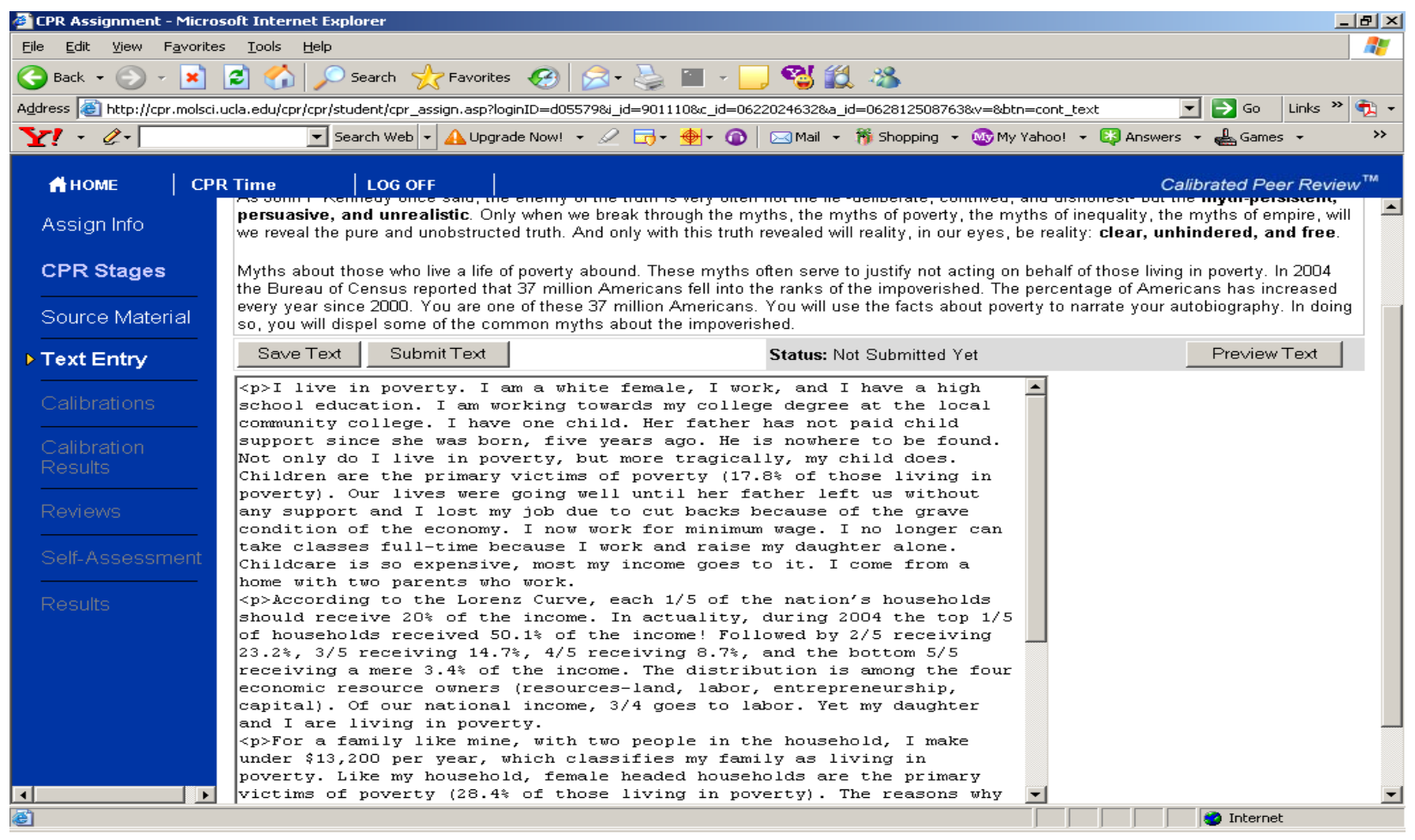

Step 5. Write the rubrics, or calibration questions, for assessing the written assignment. A question may be style or content related; may be a forced choice or constructed response and may require validation evidence from the assignment. 


\section{Question List}

These are the questions that will appear in your assignment. To customize, click on the question text.

1. Is the assignment written in an autobiographic--first person storytelling style?

2. Is the relationship between the distribution of income and the existence of poverty clearly explained?

3. How many of the 2004 household income shares are identified correctly ( top one-fifth of households possess $50.1 \%$ of all income; the second-fifth possesses $23.2 \%$; the third-fifth possesses $14.7 \%$; fourthfifth possesses $8.7 \%$ and bottom one-fifth possesses $3.4 \%$ )?

\begin{tabular}{|c|c|}
\hline Type & $\begin{array}{c}\text { Explanation } \\
\text { Required }\end{array}$ \\
\hline Style & \\
\hline Content & $\mathbf{X}$ \\
\hline Content & \\
\hline & \\
\hline
\end{tabular}

Step 6. Write and submit Three Calibrations and prepare an Answer Key (rubrics) for each calibration.

\begin{tabular}{|l|l|}
\hline Chose a calibration to create an answer key and add student feedback. & Status \\
\hline High Quality Calibration & Finished \\
\hline Middle Quality Calibration & Finished \\
\hline \hline Low Quality Calibration & Finished \\
\hline
\end{tabular}

\section{Answer the following questions (required) and add feedback (optional):}

1. Is the assignment written in an autobiographic--first person story-telling style?

(c) Yes

\section{Feedback (optional)}

I w as eight years old and in the third grade in 2004. I lived on First $S_{-}$

A Student View Of The Calibration Phase: 


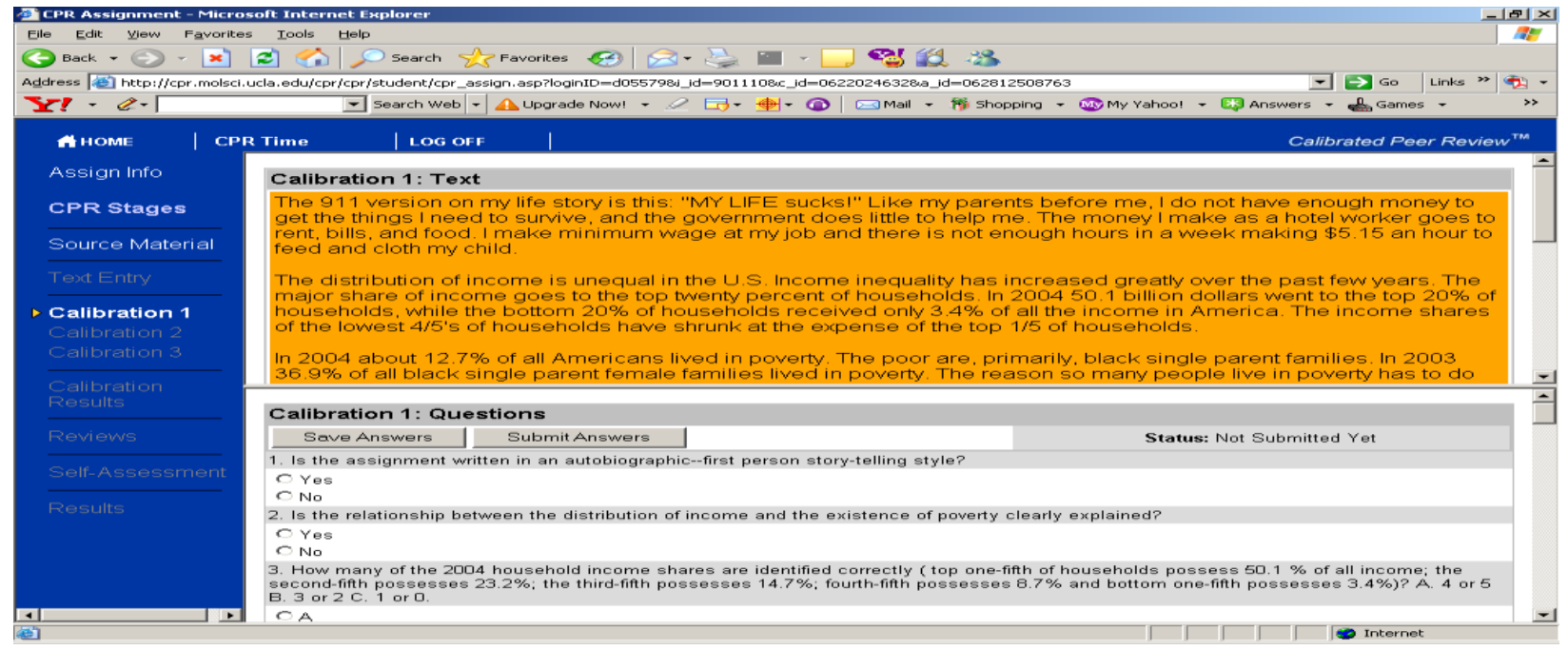

\title{
$2^{\mathrm{ND}}$ : ACTIVATING THE ASSIGNMENT:
}

Activating the writing assignment is simplistic and forced by the software.

\section{Select Assignment $>2$. Scoring $>3$. Word Count $>4$. Grade $>5$. Timing $>6$. Participation}

Course: ECON 200-Sp2007

Next >

Select a master assignment

\begin{abstract}
$\begin{aligned} & \text { Master } \\ & \text { assignment: }\end{aligned}$ It Just Isn't So: My Autobiography (4/07) [Preview]
[
\end{abstract}
New title:

It Just Isn't So: My Autobiography (4/07)

\section{Select Assignment $>2$. Scoring $>3$. Word Count $>4$. Grade $>5$. Timing $>6$. Participation}

\section{Select a Scoring Template}
1. Low Difficulty [View]
2. Moderate Difficulty [View]
3. High Difficulty [View]

The Scoring Template allows the instructor to determine the criteria for Mastery at each phase, calibration, peer review and self-assessment, by establishing the amount of deviation allowed from the Rating calculated by the software. Student ratings can NOT deviate by more than 3.0 points from the AVERAGE RATING to receive full 
credit in the three review stages with low difficulty; by not more than 2.5 points with moderate difficulty and by not more than 2.0 points with high difficulty.

\section{Select Assignment $>2$. Scoring $>3$. Word Count $>4$. Grade $>5$. Timing $>6$. Participation}

$\nabla$ Set the word count

Directions: You must determine a minimum and maximum word count for student texts. Texts of any length can be saved, but only texts meeting the word length requirements can be submitted. By default CPR displays rounded word counts approximately $25 \%$ above and below the average calibration word count.

Average word count of calibrations = 996

Minimum Word Count $=$

500

Maximum Word Count $=$

1200

The instructor establishes the word count of the assignment. A student whose text submission falls outside the parameters will be prompted to make the necessary adjustment before the assignment is accepted.

\section{Select Assignment $>2$. Scoring $>3$. Word Count $>4$. Grade $>5$. Timing $>6$. Participation}

Set the overall grade

Directions: Enter the points you want associated with each assignment stage. All points must sum to 100 . Each point total can range from 0 to 100 .

1. Text quality:

2. Calibrations:

3. Reviews:

4. Self-assessment:

\author{
$\sqrt{30}$ points \\ 25 points over 3 Calibrations \\ 25 points over 3 Reviews \\ 20 points \\ TOTAL: $\sqrt{100}$ must sum to 100 points
}

Emphasis is placed on the stages of the process by assigning higher or lower point value. In this example, the compliance to the writing assignment requirements receives emphasis. 


\section{Select Assignment $>2$. Scoring $>3$. Word Count $>4$. Grade $>5$. Timing $>6$. Participation} Det timing

Directions: Enter the times that will regulate access to this assignment. The three times will break the assignment into two sections. During the first section students will view the source material and enter text. During the second stage students will complete the calibrations, reviews, and self-assessment. NOTE: CPR times are based on the CPR server clock. Get CPR timestamp.

\begin{tabular}{|c|c|c|c|c|c|c|c|c|c|c|}
\hline \multirow{2}{*}{$\begin{array}{c}\text { Time } \\
\text { Assignment Start Time: }\end{array}$} & \multicolumn{2}{|c|}{ Month } & \multicolumn{2}{|c|}{ Day } & \multicolumn{2}{|c|}{ Year } & \multicolumn{2}{|c|}{ Hour } & \multicolumn{2}{|c|}{ Minute } \\
\hline & April & $\nabla$ & 6 & - & 2006 & + & 12 & 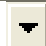 & 35 & 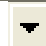 \\
\hline
\end{tabular}

Assignment Start to Text Entry End: Students view source material and enter their text.

Text Entry End Time:

\begin{tabular}{|c|c|c|c|c|c|c|c|c|c|}
\hline April & 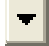 & 8 & 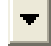 & 2006 & 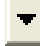 & 12 & - & 35 & 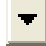 \\
\hline
\end{tabular}

Text Entry End to Assignment End: Students complete the calibrations, reviews, and self-assessment.

Assignment End Time:

\begin{tabular}{|c|c|c|c|c|c|c|c|c|c|}
\hline April & $\nabla$ & 11 & $\nabla$ & 2006 & 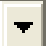 & 06 & - & 00 & $\nabla$ \\
\hline
\end{tabular}

The main server for the $\mathbf{C} \mathbf{P} \mathbf{R}^{\mathbf{T M}}$ software is housed at UCLA, therefore, the internal time stamp reflects west coast time (USA). Students may need to be reminded of this discrepancy at the start of each assignment.

\section{Select Assignment $>$ 2. Scoring $>3$. Word Count $>$ 4. Grade $>$ 5. Timing $>6$. Participation}

Set instructor participation

Will you participate in this assignment as a student?

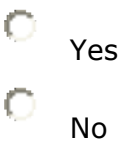

NOTE: If you decide to participate, you must complete all stages of the assignment.

A Student View Of Review Results Viewable Once The Assignment End Time Arrives. 


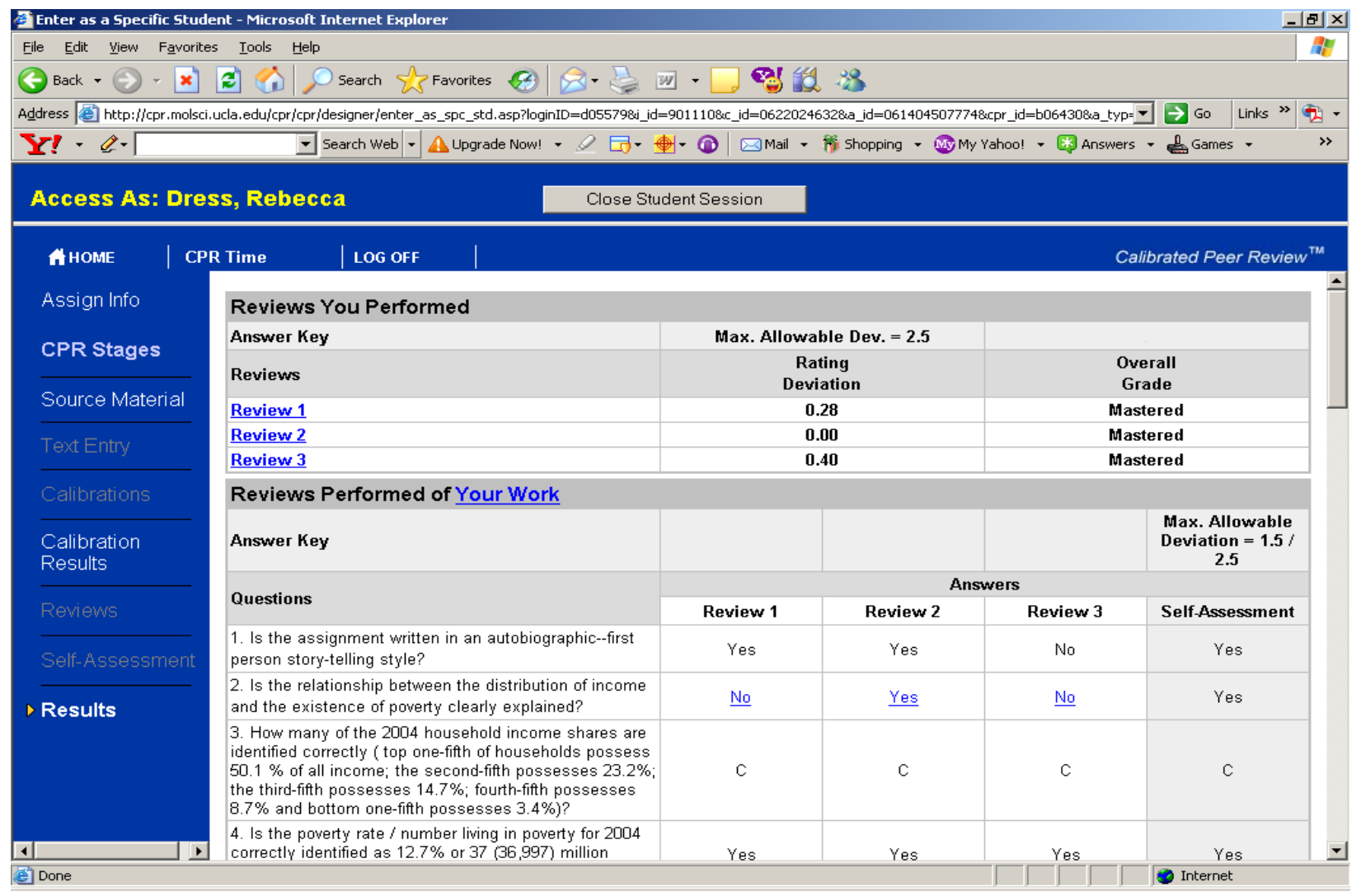

The paper Quick Start for Administrators available at the $\mathbf{C P R}^{\mathrm{TM}}$ website provides directions on how to add users. Once added, student names remain in the system allowing access by any course instructor using CPR at the institution. Logging into the system the first time as "New Users," students obtain their unique CPR ID, a six digit letter + number code. Student progress through the CPR tour and quiz can be monitored by the instructor. Two papers are downloadable from the $\mathbf{C P R}^{\mathrm{TM}}$ website, Student Handout and Student Results, to orient students to the process.

\section{WHY DOES IT WORK?}

Carlson and Berry (2003) note that "a $\mathbf{C P R}^{\mathrm{TM}}$ session contains two very distinct types of instructional activities: (1) a construction of a written product to fit a fully-specified rhetorical situation and (2) participation in a collaborative, evaluative exercise that culminates in self-reflection."

The construction of a well-developed writing assignment holds the potential to challenge students' higher order thinking skills such as application (use of information to solve problems, transfer abstract ideas to practical situations); analysis (breaking down situations or ideas); synthesis (assembling information in creative or original ways) and evaluation (developing and supporting conclusions within the context of values). The CPR process teaches students to write more coherently by providing guiding questions, scaffolding, for building well-written assignments.

Once student text has been submitted, the $\mathbf{C P R}{ }^{\mathrm{TM}}$ disaggregates the review into a step-by-step procedure using an authentic double-blind anonymous review process employed by academia. How well students perform ultimately depends on how well students read and evaluate. First, students are "calibrated" as reviewers. Using the calibration questions which function as grading rubrics and are ideally premised on the learning objectives, students proceed to "grade" the three instructor essays. One high quality calibration reflects the best grading key the 
instructor can make. The other two reflect common misconceptions, superficial answers, omissions and errors with care given to make a distinction between the mid-quality and low quality calibrations. Acceptable reviewers move on to the anonymous peer review stage; otherwise, the student passes through the calibrations a second time. Extensive formative feedback built into the iterative calibration process strengthens content understanding, clarifies student thinking and corrects misunderstanding.

Moving into the peer review phase taps another skill set that includes evaluation, judging against standards, and justification of judgments which is used to critique and validate the science process but is rarely taught. Wolfe in his study of Online Student Peer Reviews (2004) enumerates the advantages of student being peer reviewers.

1. Students see things from the teacher's perspective, that is, other students' work, by having the same "grading" experience typically monopolized by the teacher.

2. Students gain a better understanding of the grading process when the shroud is dissipated by being required to systematically apply the rubrics and, potentially making it easier for the student to accept constructive criticism.

3. Students interact with each other in ways that help to build community.

4. Students get quick and plentiful feedback, effectively, removing the bottleneck of waiting for the instructor to grade all the written assignments.

5. Students see the distribution in the quality of the work submitted by their classmates, potentially, helping them understand what more is required of them.

6. Students with superior content knowledge and writing skills provide their classmates with excellent writing samples.

7. The teacher takes on a supervisory role paying more attention to designing the assignments and keeping the course moving in the right direction.

In the final phase, students self-assess. An evaluation by Teacher Education (2003) lauds this phase as a culminating strength of CPR, "[t]he iterative nature of this process promotes meta-cognitive thinking about the content and structure of one's own writing in response to the original assignment."

Once the timing on the assignment expires, the software generates individual student reports and instructor reports with detailed data on performance. Carlson and Berry (2003) assert that $\mathbf{C P R}^{\mathbf{T M}}$ draws its significance both as a learning tool and as an assessment tool from the software's ability to "informate," that is, collect and interpret data on its own usage.

Student progression through a $\mathbf{C P R}^{\mathrm{TM}}$ assignment is meticulously tracked from the Start Time to the Assignment End Time. Instructors have on demand access and can readily monitor class progress through the four phases; text entry, calibrations, reviews and self-assessment.

\begin{tabular}{|c|c|c|c|c|c|c|}
\hline \multicolumn{7}{|c|}{ Student Progress } \\
\hline Student & $\begin{array}{l}\text { Text } \\
\text { Entry }\end{array}$ & Calibrations & $\begin{array}{c}\text { Evaluate } \\
\text { Calibrations }\end{array}$ & Reviews & $\begin{array}{c}\text { Self- } \\
\text { Assessment }\end{array}$ & Finished \\
\hline 30. Amanda & -- & -- & -- & -- & -- & Not Started \\
\hline 31. Nathan & $\mathbf{x}$ & $\mathbf{x}$ & $\mathbf{x}$ & $\mathbf{x}$ & $\mathbf{x}$ & Yes \\
\hline 32. Ryan & $\mathbf{x}$ & $\mathbf{x}$ & $\mathbf{x}$ & $\mathbf{x}$ & $\mathbf{x}$ & Yes \\
\hline Statistics & $\begin{array}{l}\text { Text } \\
\text { Entry }\end{array}$ & Calibrations & $\begin{array}{l}\text { Evaluate } \\
\text { Calibrations }\end{array}$ & Reviews & $\begin{array}{c}\text { Self- } \\
\text { Assessment }\end{array}$ & Finished \\
\hline $\begin{array}{l}\text { Completion } \\
\text { Rates }\end{array}$ & $\begin{array}{c}91 \% \\
(29 / 32)\end{array}$ & $91 \%(29 / 32)$ & $91 \%(29 / 32)$ & $\begin{array}{c}91 \% \\
(29 / 32)\end{array}$ & $91 \%(29 / 32)$ & $\begin{array}{c}91 \% \\
(29 / 32)\end{array}$ \\
\hline
\end{tabular}


Each student receives specific feedback on his/her performance on peer work, peers' review of his/her own work, scores at each phase and an overall score for the assignment. The exact identification of peer reviewers, the reviewer's competency index (RCI ranging from a high of 6 to a low of 1) and each reviewer's score earned for the particular stage is revealed only to the instructor.

\begin{tabular}{|l|c|c|}
\hline Reviews You Performed & Max. Allowable Dev. = 2.5 \\
\hline Answer Key & $\begin{array}{c}\text { Rating } \\
\text { Deviation }\end{array}$ & $\begin{array}{c}\text { Overall } \\
\text { Grade }\end{array}$ \\
\hline Reviews & 0.36 & Mastered \\
\hline Review 1 & 0.00 & Mastered \\
\hline Review 2 & 1.16 & Mastered \\
\hline Review 3 & & \\
\hline
\end{tabular}

Reviews Performed of Your Work

\section{Answer Key}

Max. Allowable

\begin{tabular}{|c|c|c|c|c|}
\hline Answer Key & & & & $\begin{array}{c}\text { Deviation }=1.5 / \\
2.5\end{array}$ \\
\hline \multirow{2}{*}{ Questions } & \multicolumn{4}{|c|}{ Answers } \\
\hline & Review 1 & Review 2 & Review 3 & Self-Assessment \\
\hline $\begin{array}{l}\text { 1. Is the assignment written in an autobiographic-- } \\
\text { first person story-telling style? }\end{array}$ & No & No & No & No \\
\hline $\begin{array}{l}\text { 2. Is the relationship between the distribution of } \\
\text { income and the existence of poverty clearly } \\
\text { explained? }\end{array}$ & $\underline{\text { Yes }}$ & $\underline{\text { Yes }}$ & $\underline{\text { Yes }}$ & Yes \\
\hline
\end{tabular}

\begin{tabular}{|l|c|c|c|c|}
\hline 25. How would you rate this text? & 5 & 6 & 7 & 5 \\
\hline Weight Applied to Ratings & 0.85 & 1.00 & 0.85 \\
\hline Weighted Average Text Rating & & 6.00 & \\
\hline
\end{tabular}

\begin{tabular}{|c|c|c|}
\hline \multicolumn{3}{|c|}{ Scores and Overall Grade } \\
\hline Stage & Performance & Score \\
\hline Text Entry & Avg. Weighted Text Rating $=\mathbf{6 . 0 0}$ & 12.00 out of 20 \\
\hline Calibrations & Avg. Calibration Deviation $=1.67$ & 30.00 out of 30 \\
\hline Reviews & Avg. Review Deviation $=\mathbf{0 . 5 1}$ & 30.00 out of 30 \\
\hline Self-Assessment & Self-Assessment Deviation $=\mathbf{1 . 0 0}$ & 20.00 out of 20 \\
\hline \multicolumn{2}{|l|}{ Overall Score } & 92.00 out of 100 \\
\hline
\end{tabular}

Of the three reports generated: a general Student Results report, an expanded overall Student Results report and the Problem List, the most important may well be the Problem List. It alerts the instructor when a student received only one peer review, the two assigned reviewers had deviations that exceed those allowable or the reviewer(s) earned a reviewer competency index of 2 or less on the calibrations. The value of the List is in its preemptive nature alerting the instructor to potential student complains on scoring. To maintain instructor control over the process, $\mathbf{C P R} \mathbf{R}^{\mathrm{TM}}$ has been designed with backdoor options allowing access for timely adjustments as well as view and re-evaluate of student work. 


\begin{tabular}{|c|c|c|c|c|c|c|c|c|c|c|c|c|c|c|}
\hline \multicolumn{15}{|c|}{ Class Averages: More Info } \\
\hline \multirow{2}{*}{ Categories } & \multirow{2}{*}{$\begin{array}{l}\text { Overall } \\
\text { Grade }\end{array}$} & \multicolumn{2}{|c|}{ Text } & \multicolumn{7}{|c|}{ Calibrations } & \multicolumn{2}{|c|}{ Reviews } & \multicolumn{2}{|c|}{$\begin{array}{c}\text { Self- } \\
\text { Assessment }\end{array}$} \\
\hline & & Rating & Score & \multicolumn{2}{|c|}{$\begin{array}{c}\% \\
\text { Style }\end{array}$} & \multicolumn{2}{|c|}{$\begin{array}{c}\% \\
\text { Content }\end{array}$} & $\begin{array}{l}\text { Avg. } \\
\text { Dev. }\end{array}$ & Score & RCI & $\begin{array}{l}\text { Avg. } \\
\text { Dev. }\end{array}$ & Score & Dev. & Score \\
\hline $\begin{array}{l}\text { Class } \\
\text { Averages }\end{array}$ & 78.93 & 4.47 & 8.93 & \multicolumn{2}{|c|}{100.00} & \multicolumn{2}{|c|}{71.82} & 1.38 & 22.76 & 4.31 & 0.74 & 29.31 & 1.12 & 17.93 \\
\hline \multicolumn{15}{|l|}{$\Delta \underline{\text { Top }}$} \\
\hline \multicolumn{10}{|c|}{ Student Results: Less Info } & \multicolumn{4}{|c|}{ Display Type: } & Reload \\
\hline \multicolumn{3}{|l|}{ Name } & \multicolumn{2}{|c|}{$\begin{array}{l}\text { Overall } \\
\text { Grade }\end{array}$} & \multicolumn{2}{|c|}{$\begin{array}{c}\text { Text } \\
\text { Rating }\end{array}$} & & \multicolumn{2}{|c|}{$\begin{array}{c}\text { Reviewer } \\
\text { Competency } \\
\text { Index (RCI) }\end{array}$} & \multicolumn{3}{|c|}{ Finished } & \multicolumn{2}{|c|}{$\begin{array}{l}\text { Viewed } \\
\text { Results }\end{array}$} \\
\hline \multicolumn{3}{|l|}{ Key } & \multicolumn{2}{|c|}{$\begin{array}{c}\text { Out of } \\
100\end{array}$} & \multicolumn{2}{|c|}{ Out of 10} & & \multicolumn{2}{|c|}{$\begin{array}{c}6 \text { (best) - } 1 \\
\text { (worst) }\end{array}$} & & & & & \\
\hline \multicolumn{3}{|l|}{ 1. Brandon } & \multicolumn{2}{|c|}{--} & \multicolumn{2}{|c|}{--} & & \multicolumn{2}{|c|}{--} & \multicolumn{3}{|c|}{ Not Started } & \multicolumn{2}{|c|}{ No } \\
\hline \multicolumn{2}{|l|}{ 2. Joshua } & & \multicolumn{2}{|c|}{78.72} & 4. & 36 & & & 4 & & Yes & & & es \\
\hline Class Avera & 5 Less In & & & & & & & & & & & & & \\
\hline Class Avera & & & 8.93 & 4.2 & & & 4.31 & & & $91^{\circ}$ & $\%(29)$ & 32) & & $\begin{array}{c}81 \% \\
(26 / 32)\end{array}$ \\
\hline
\end{tabular}

\section{Assignment Problem List}

Explanation: Each student in this list has a potential problem with his or her assignment.

Student

1. Amanda

\section{One Reviewer}

The student's text was reviewed by only one reviewer.

\section{Two Reviewers}

The student's text was reviewed by two reviewers. reviewers has an $\mathrm{RCI}$ The students' reviews exceeded the allowed deviation.

\section{Low RCI Reviewer}

One or more of the of 2 or less.
YES

Results from CPR Assignments during Sp 06

\begin{tabular}{|l|c|c|c|c|c|c|c|c|c|c|}
\hline \multicolumn{1}{|c|}{ Template } & $\begin{array}{c}\text { Overall } \\
\text { Grade }\end{array}$ & $\begin{array}{c}\text { Text } \\
\text { Rating }\end{array}$ & $\begin{array}{c}\text { Text } \\
\text { Score }\end{array}$ & $\begin{array}{c}\text { Cal. } \\
\text { Dev. }\end{array}$ & $\begin{array}{c}\text { Cal. } \\
\text { Score }\end{array}$ & RCI & $\begin{array}{c}\text { Review } \\
\text { Dev. }\end{array}$ & $\begin{array}{c}\text { Review } \\
\text { Score }\end{array}$ & $\begin{array}{c}\text { SA } \\
\text { Dev. }\end{array}$ & $\begin{array}{c}\text { SA } \\
\text { Score }\end{array}$ \\
\hline Low Difficulty \#1 & 86.93 & 5.47 & 10.93 & 1.05 & 28.67 & 5.53 & 0.99 & 29.33 & 1.14 & 18 \\
\hline Low Difficulty \#2 & 87.14 & 5.57 & 11.14 & 1.12 & 27 & 5.33 & 0.87 & 29.67 & 0.84 & 19.33 \\
\hline $\begin{array}{l}\text { Moderate } \\
\text { Difficulty \#3 }\end{array}$ & 78.93 & 4.47 & 8.93 & 1.38 & 22.76 & 4.31 & 0.74 & 29.31 & 1.12 & 17.93 \\
\hline
\end{tabular}

\begin{tabular}{|c|c|c|c|c|c|c|c|c|c|c|}
\hline Changes & \multicolumn{1}{|c|}{} \\
\hline 1 to 2 & $0 \%$ & $2 \%$ & $2 \%$ & $7 \%$ & $-6 \%$ & $-4 \%$ & $-12 \%$ & $1 \%$ & $-26 \%$ & $7 \%$ \\
\hline 2 to 3 & $-9 \%$ & $-20 \%$ & $-20 \%$ & $23 \%$ & $-16 \%$ & $-19 \%$ & $-15 \%$ & $-1 \%$ & $33 \%$ & $-7 \%$ \\
\hline
\end{tabular}


On average students experienced positive gains between CPR assignments 1 and 2 when the scoring template remained at a low difficulty level. To master the calibrations, students are allowed no more than 3 deviations, while self-assessment allows no more than 2 deviations for full credit. The moderate difficulty scoring template reduces the deviations by 0.5 points from the low difficulty template. Between assignments 1 and 2 student performance improved in all categories except the increase in calibration deviations (7\%) with a corresponding reduction in calibration score $(-6 \%)$ and a reduction in RCI by $-4 \%$. Student performance continued improvement between assignments 2 and 3 only in peer review deviations (-15\%).

Overall class averages have, also, shown incremental increases over the past three semesters (F05, 73.33; Sp06, 87.14; F06, 88.42).

\section{$\mathrm{CPR}^{\mathrm{TM}}$ experience: What do students say?}

A column posted at Technology Media Corporation (2006) condemns $\mathbf{C P R}^{\text {TM }}$ for reducing students' writing skills and discouraging writing confidence, while simply increasing student writing volume. Student experience since fall 2005 while mixed has been favorable on the whole.

J. Chambers: Also, I hated the peer review concept!!!!

S. Mulvin: The only thing that did not work for me in those areas was the way they (the CPR papers) were graded. For some reason, it did not make sense to me. To be frank, I felt my papers were very well done. I answered every single question that was required and I answered it correctly. However, the questions asked for the reviewers to answer were just not what I had in my paper, but it should not have mattered. I still answered the questions correctly, but in a different way, and maybe I did not elaborate on the issue, but I still had the required questions answered. I felt like I got "scammed," and was receiving worse grades than I deserved.

M. Barone: One of the things I found most useful about this class were the peer evaluations we had to give each other on our papers. This was helpful because for the first time in my writing history I got real feedback about my writing.

B. McGory: At first, I honestly thought, "Economics...this is going to be really boring." The excitement began when we started talking about economic issues we have in society. I liked the idea of bringing the Calibrated Peer Review into the course, because I love working with computers. The Calibrated Peer Review assignment helped me become a better proofreader along with being able to point out and correct my own mistakes within my own writing which is a good quality to have.

G. Van Wagnen: I feel that from the beginning to the end of this course my writing skills and comprehension skills have become more developed. At first I did not care for the Calibrated Peer Review that we used, but eventually I learned from it. I found that in the end it did help. It helped me take the material taught and put it into papers that I helped me understand the material better. You can sit in class and listen to the instructor all day long, but to really understand the information and facts the papers helped do that. Another thing that I found the Calibrated Peer Review program helped me do was read other's work and be able to critique and understand what was implied. By reading other person's work it helped point out areas where I needed a little more improvement. I found that reading other person's work and reading the different ways that they went about writing their papers helped me learn about the material that was given. One person may have taken a different approach in incorporating the material and this helped me in future papers to be able to add different techniques that I would not normally

S. Miller: The $C P R$ program that we were introduced to has helped me write in a more professional way by learning how to grade one another's papers and evaluate them correctly. The $C P R$ allowed me to see how my peers were writing and what types of information the professor wanted to be in the paper. Now I have a 
better feel for how professors' grade papers, what is expected of me and what type of information is needed for the paper(s) to receive full credit for the assignment.

As a user of $\mathbf{C P R}^{\mathbf{T M}}$ the three most frequently vocalized issues include an increased student workload, unreliable feedback and biased feedback. The $\mathbf{C P R}^{\mathrm{TM}}$ process is largely an unknown both on my campus and in the field of economics. To offset the increased need for computer time, I typically allow ten days between the receipt of the paper topic and the assignment end time. To minimize the negative impact of "learning curve" issues, I choose a "low difficulty" scoring template for the first two assignments and ratchet the scoring template up for the third assignment. And Prichard (2005) is forthright in acknowledging that $\mathbf{C P R}^{\mathbf{T M}}$ “.... requires more student engagement and autonomy in the writing and review process than traditional assignments" which students may interpret as "time-consuming."

In-class time must be devoted to helping students discern the intent of feedback as well as the distinction between constructive rubric-based comments and destructive comments. Before the first $\mathbf{C P R}^{\mathbf{T M}}$ assignment I make expectations clear on how to evaluate using a sample essay, how to use the rubric questions, how to calculate the overall rating score and what constitutes constructive feedback. When the basis for judging is well planned and well understood, student peer assessment should closely resemble instructor assessment. A random sampling of student work can easily "test" validity and reliability of results. Additionally, providing students an opportunity to revise their assignments for extra credit ( +5 points above the 30 points) and making the "quality" of peer review comments count as class participation helps level the complaint field.

While $\mathbf{C P R}^{\mathbf{T M}}$ enables frequent writing assignments without a parallel increase in instructor grading load through automation, instructors carry a heavier load on the front-end of the process. The most demanding step for $\mathrm{CPR}^{\mathrm{TM}}$ is the planning phase. For the first assignment anticipate between eight and ten hours for assignment creation, calibration phase and activation steps. Errors remaining in the assignment once activated can not only complicate the student review process but potentially negate it. And be reminded that to dissuade cheating, the creation of unique assignments or at least tweaking an old one is a must for each new semester. Things can go wrong and when they do--the technical support team at UCLA $<$ http://www.ccsf.cc.ca.us/Departments/Chemistry/su/flash/cprhelp instr.htm $>$ is readily accessible for users of $\mathbf{C P R}^{\mathrm{TM}}$.

\section{CONCLUSION}

Despite the powerful benefits writing offers as an active learning strategy, many instructors have been reluctant to release it full potential. Calibrated Peer Review ${ }^{\mathrm{TM}}$ (CPR), however, offers an awesome opportunity to minimize the "grading pain for the instructor," while encouraging "writing gain for students!" The overall goal of $\mathbf{C P R}^{\mathrm{TM}}$ is to produce stronger writers and readers. $\mathbf{C P R}^{\mathrm{TM}}$, s asynchronous, discipline and level independent electronic learning environment creates an extraordinary opportunity for students to learn content by writing about content, learn content by reading for comprehension and learn content through self-reflection. $\mathbf{C P R}^{\mathrm{TM}}$ is in my estimation a win-win instructional tool for both students and instructors.

\section{REFERENCES:}

1. Bloom, B. M. Engelhart, E. Furst, W. Hill and D. Krathwohl. 1956. Taxonomy of Educational Objectives: The Classification of Educational Goals. Handbook I: Cognitive Domain. New York, NY: Longmans, Green and Company.

2. Cameron, Beverly. 1998. Active and Cooperative Learning Strategies for the Economics Classroom. W. B. Walstad and P. Saunders (Eds.). Teaching Undergraduate Economics: A Handbook for Instructors. Boston: Irwin / McGraw-Hill. 227-243.

3. Carlson, Patricia and Frederick C. Berry. 2005. Calibrated Peer Review (CPR) A Tool for Integrating Meaningful Writing Assignments into Technical Courses. Proceedings of the NCIIA $9^{\text {th }}$ Annual Meeting. 17-19 March 2005. San Diego, CA. pp 269-276. 
4. Carlson, Patricia and Frederick C. Berry. 2003. Calibrated Peer Review ${ }^{\mathrm{TM}}$ and Assessing Learning Outcomes. Proceedings of the 33rd ASEE/IEEE Frontiers in Education Conference, Boulder, CO. 5-8 November 2003. F3E-1-6.

5. Cervato, Cinzia, James A. Rudd and Robert Ridky. 2003. Calibrated Peer Review for the Earth Sciences: A Prototype Assignment on Earthquakes and Plate Tectonics. Abstracts with Program (Geological Society of America) 35(6): 441.

6. Chapman, Orville L and Michael A. Fiore. 2001. Calibrated Peer Review ${ }^{\mathrm{TM}}$ : A writing and critical thinking instructional tool. The White Paper: A Description of CPR. http://cpr.molsci.ucla.edu/ . $12 \mathrm{March}$ 2001 updated.

7. Elbow, P. 1994. Writing for learning--not just for demonstrating learning. University of Massachusetts, Amherst, 1-4.

8. Furman, Burford and William Robinson. 2003. Improving Engineering Report Writing with Calibrated Peer Review ${ }^{\mathrm{TM}}$. Proceedings of the 33rd ASEE/IEEE Frontiers in Education Conference, Boulder, CO. 5-8 November 2003. F3E-14-15.

9. Goffe, William L. and Kim Sosin. 2005. Teaching with Technology: May you Live in Interesting Times Journal of Economic Education, 36(3): 278-291.

10. Heise, Elizabeth A., Amanda Palmer-Julson and Tim M. Su. 2002. Calibrated Peer Review Writing Assignments for Introductory Geology Courses. Abstracts with Programs, The Geological Society of America, 34 (6): 345.

11. Palmini, Dennis J. 1996. Using Rhetorical Cases to Teach Writing Skills and Enhance Economic Learning. Journal of Economic Education, 27(3): 205-212.

12. Petr, Jerry L. 1998. Student Writing As A Guide to Student Thinking. W. B. Walstad and P. Saunders (Eds.). Teaching Undergraduate Economics: A Handbook for Instructors. New York: Irwin / McGrawHill. 227-243.

13. Pelaez, Nancy J. 2001. Calibrated Peer Review in General Education Undergraduate Human Physiology. Accessed 7 October 2006. Available at www.ed.psu.edu/CI/Journals/2001aets/su2_01_pelaez.rtf

14. Pelaez, Nancy J. 2002. Problem-based Writing with Peer Review Improves Academic Performance in Physiology. Advances in Physiology Education, 26 (3):174-184.

15. Perry, W. 1981. Cognitive and Ethical Growth: The Making of Meaning. In A.W. Chickering et al. (Eds.), The Modern American College, San Francisco, CA: Jossey-Bass.

16. Prichard, J. R. 2005. Writing to Learn: An Evaluation of the Calibrated Peer Review ${ }^{\mathrm{TM}}$ Program in Two Neuroscience Courses. The Journal of Undergraduate Neuroscience Education. 4 (1): A34-A39.

17. Robinson, Ralph. 2001. Calibrated Peer Review ${ }^{\mathrm{TM}}$ : An Application to Increase Student Reading \& Writing Skills. American Biology Teacher. 63 (7): 474-480.

18. Russell, Arlene A. 2005. Calibrated Peer Review ${ }^{\text {TM }}$-A Writing and Critical Thinking Instructional Tool. Invention and Impact: Building Excellence in Undergraduate STEM Education. AAAS.

19. Salemi, Michael K. 2002. An Illustrated Case for Active Learning. Southern Economic Journal, 68(3): 721-731.

20. Teacher Education. July 13, 2003. Review of Calibrated Peer Review. Accessed 10/07/06. Available at http://merlot.org/merlot/viewCompositeReview.htm?id=150715.

21. Technology Media Corporation Column: Calibrated Peer Review does not Improve Writing. 22 March 2006. Accessed 10/07/06. Available at www.tmcnet.com/usubmit/2006/03/22/1482503.htm.

22. Walstad, William B. 2005. Assessment of Student Learning in Economics. William E. Becker, Michael Watts and Suzanne R. Becker (Eds.). Teaching Economics: More Alternatives to Chalk and Talk. Cheltenham UK: Edward Elgar Publishing, LTD.

23. Wight, Jonathan. 1999. Using Electronic Data Tools in Writing Assignments. Journal of Economic Education, 30(1): 21-27.

24. Wise, John and Seong Kim. 2004. ASEE Annual Conference \& Exposition: Engineering Education Reaches New Heights, Salt Lake City, UT; 20-23 June 2004.

25. Wolfe, William J. 2004. Online Student Peer Reviews. Proceedings for ACM SIGITE Annual Conference. Salt Lake City, UT, 28-30 October 2004. 